\title{
Research on Optimization of Graphical Scheme for Large Plane Cross Signs
}

\author{
Yifei Zhao, Yanfei Zhang* \\ School of Highway, Chang'an University, Xi'an, Shanxi, 710064, China
}

\begin{abstract}
In order to find a practical graphical layout of the plane cross sign and the corresponding intersection road information expression method, and effectively solve the multi-attribute information transmission problem of intersecting roads, the drivers' eye movement characteristics and the visual response time was analyzed when recognizing the signs with different graphic scheme designs and intersecting road information expressions. The tests were divided into static test and dynamic test by using SMT ETG 2W and Tobbi X20-30 eye trackers. The study found that under the condition of three road name information, comparing the graphical layout with both the intersecting road number and road name and the graphical layout which expressed none information of intersecting road for the large plane cross signs, it is equivalent to the addition of two pieces of information. And the conclusion for six road name information is more obvious.
\end{abstract}

\section{Introduction}

With the growth of the domestic urbanization construction speed and the continuous expansion of scale, many areas that were not originally used for urban construction are becoming part of the city at an unprecedented rate. As a result, in addition to continuing to play the transportation function of the main road, many national highways around the city have gradually become part of the urban road and have been given the name of the urban road. However, in the current specifications of China, the layout information requirements for the plane cross signs of the general road are only simply considered the single case of the national provincial road or the urban road (with no route coincidence). It does not consider the multi-attribute problem that may exist on the same road. Therefore, it may lead to the omission of the expression of some important guiding information when guiding the actual engineering design. And it is troublesome for drivers who are not familiar with the local road conditions but are increasingly dependent on the vehicle navigation system. These would reduce the level of service for the road and may also threaten driving safety. The above problems are particularly evident in the large plane cross signs that need to express more path information.

Since 2000, foreign research on signs has tended to analyze the impact of traffic signs on drivers from the perspective of psychology and cognition [1-2], and analyze the influence of traffic environment and driver's group characteristics on sign layout design. At the same time, the relationship between the time required for the drivers to read the sign and the amount of sign information has also been studied, and the relevant model was established [3-4]. The studies have shown that the recognition time increases with the increase in the amount of information on the sign.

Domestic research in the area started late, but it has developed rapidly and shown a multi-flowering situation. Through the lab simulation, simulation experiments and real vehicle experiments, the reflective materials of traffic signs [5], the amount of information transmitted by the signs [6], the text format [7] and the layout of the sign [8] have been studied. However, there are few studies on the visibility and safety of the graphical layout for the large plane cross sign that can carry more road attribute information.

For the above reasons, how to design a graphical layout for the large plane cross sign that can carry more road attribute information without significantly increasing the drivers ' cognitive load is a very worthy research field. Therefore, the research has compared the information reading times of three kinds of large plane cross signs with different graphical layouts by organizing indoor simulation experiments, which aims to find a practical graphical layout of the plane cross sign and the corresponding intersection road information expression method, and effectively solve the multi-attribute information transmission problem of intersecting roads.

\section{Test preparation}

\subsection{Layout design of advance exit signs}

In order to scientifically reflect the difference in the visual reaction time of the sign layouts with different 
graphic scheme design and intersecting road information expression under different information quantities, the targeted design of the sign layout to be tested in the research has been carried out. Under the conditions of three road name information and six road name information, CorelDRAW X7 drawing software has been used to design six large plane cross signs with different graphical layouts and intersecting road information expressions. The sizes of all signs and font size are the same in order to meet the national standard. Meantime, In order to avoid the interference of too simple Chinese characters or unconventional Chinese characters on the experimental results, the necessary selection of the place name information that needs to be read was made. The test layout is shown in Table 1.

Table 1. Test layout diagram.

\begin{tabular}{|c|c|c|c|}
\hline \multirow[b]{3}{*}{$\begin{array}{l}\text { Three road } \\
\text { Information }\end{array}$} & Layout form I & Layout form II & Layout form III \\
\hline & $\begin{array}{ll}\mathrm{N} & \text { Tangzhuang West Road } \\
\end{array}$ & Chuantuan West Road & \begin{tabular}{l|l}
$\mathrm{N}$ & Rongqing West Road \\
\end{tabular} \\
\hline & $\begin{array}{l}\text { Qiushi } \\
\text { Road }\end{array} \begin{array}{c}\text { Qingzhou } \\
\text { Road }\end{array}$ & $\begin{array}{l}\text { Jinli } \\
\text { Road }\end{array}-$ S106= & $\begin{array}{c}\text { Yond Roed Pingan Rood } \\
\text { Slob }\end{array}$ \\
\hline & N Tangzhuang Road Huangqu Rosd & $\stackrel{\uparrow}{N}$ Qinzhou Road Wenyuan Rosd & $\begin{array}{lll}\mathrm{N} & \text { Rongqing Road Chuntuan Road } \\
\end{array}$ \\
\hline $\begin{array}{l}\text { Six road } \\
\text { Information }\end{array}$ & Qiushi Road & Qiushi Road & Ian Road \\
\hline & Wushi Road & Jili Road ${ }^{\text {S1006 }} \longrightarrow$ Boxue Road & Fenjin Road s106 slos Chongyu Road \\
\hline
\end{tabular}

\subsection{Basic Information of Testing Drivers}

Twenty drivers with certain driving experience were selected as testers. The visual acuity of the tester was checked according to the international standard visual acuity chart E and the five-point record value, and the corrected visual acuity of all testers was above 4.9. Considering the influence of gender, age, education level and other factors on the interpretation of the interchange graphical signs, the structure of the experimenter was rationally designed. The basic information of the tester is shown in Table 2

Table 2. Basic Information of Testing Drivers.

\begin{tabular}{cccc}
\hline Item & Category & $\begin{array}{c}\text { Number of } \\
\text { People }\end{array}$ & $\begin{array}{c}\text { Percentage } \\
(\%)\end{array}$ \\
\cline { 2 - 4 } Sex & Male & 16 & 80 \\
& $\begin{array}{c}\text { Female } \\
\text { Age under 25 } \\
\text { years }\end{array}$ & 4 & 20 \\
Age & $\begin{array}{c}\text { 25years to } 50 \\
\text { years } \\
\text { Above 50 } \\
\text { years }\end{array}$ & 16 & 10 \\
Educational \\
Degree & $\begin{array}{c}\text { High school } \\
\text { and below } \\
\text { University and } \\
\text { above }\end{array}$ & 8 & 80 \\
\hline & 12 & 60 \\
\hline
\end{tabular}

\subsection{Test Equipment}

Eye tracker simulation test is a commonly used test method at home and abroad. In the experiment, the eye movement data of the testers were recorded by a manmachine system consisting of a 21 -inch computer display (15:9 aspect ratio) and a Tobii X2-30 eye tracker developed by Sweden Tobii Company, which was the static test. SMI ETG 2W eye tracker was used to check the validity of static test results, which was dynamic test.
And SMI ETG 2W eye tracker was manufactured by German SMI Company based on non-invasive video, pupil-cornea and dark pupil tracking technology.

\subsection{Experimental Method}

To minimize the interference of the surrounding environment on the testers, the experiment was arranged in an independent and quiet room. The sign layouts of the dynamic test were projected on the flat and smooth white wall by Panasonic PT-X20 projector, the vertical distance between the testers and the wall was determined according to ergonomics principle, which was about 2.5 meters.

\section{Test process}

\subsection{Static testing process}

Using Tobii X2-30 eye tracker to record the eye movement time data and trajectory results of the testers. The specific method was to organize all the testers to find out the exact position of the designated words on the sign under two kinds of information quantities including three road names and six road names in turn before a display screen with the eye tracker which was installed in advance. Taking the test under the condition of six places' name as an example. The target road name (such as Fenjin Road) that need to be read should appear first on the screen during the experiment. When the testers confirm that the target road name has been identified and then press the key to enter the reading link, all 6 graphical signs with six road names information would be shown on the screen in a random manner. During the testing process, when the testers confirm that they have found the exact location of the target road name from the test layout and see the path information on the pattern, the system would automatically switch to start randomly presenting the next test layout. After finishing each test 
group, the participants would be arranged to rest properly and then enter the next test group until they completed the test task of 18 graphical sign layouts under two information quantities.

\subsection{Dynamic testing process}

Because the experiment with Tobii X2-30 Eye Tracker belongs to static test, there may be large difference with the real road-finding scene. Therefore, in order to verify the validity of the static test results, referring to the experimental process of static test, the man-machine system consisting of SMI ETG 2W Eye Tracker and Panasonic PT-X20 projector was used to carry on the dynamic test. Dynamic test was arranged the next day of static test to reduce the influence of learning effect. In the experiment, Microsoft Power-Point was used to make dynamic images of the sign layouts to be tested, and Panasonic PT-X20 projector was used to play in the far and near mode to simulate the real road-finding scene.

\section{Data analysis and results}

According to the test method, the paper has divided the reading results of signs into two parts, and carried out comparative analysis in order to get reasonable conclusions.

\subsection{Static trajectory analysis}

Through the analysis of eye trajectory results on each sign obtained in static test, only when the testers' gaze points stay on the target words at last, and the corresponding road information also obtains the gaze points, can the results of the test be considered effective. The effective trajectory diagram of static test is shown in Figure 3. The percentage of effective trajectory diagrams obtained under each test condition is more than $91 \%$, which indicates that the eye movement time data obtained by static test is credible.
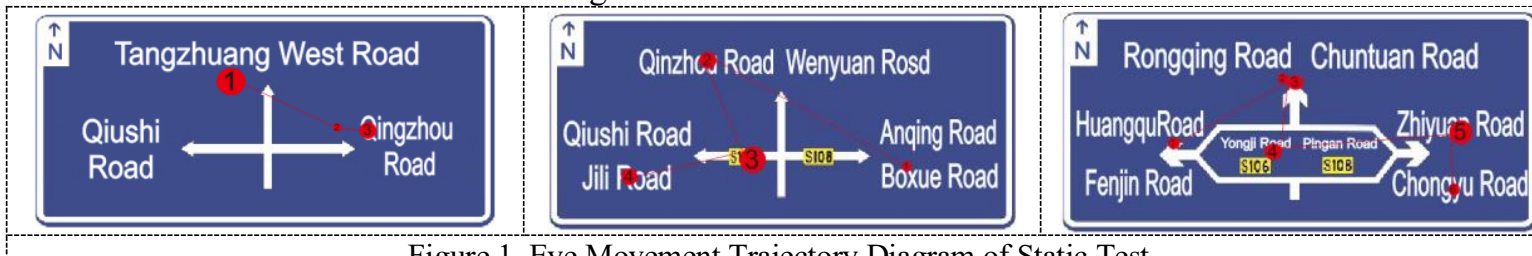

Figure 1. Eye Movement Trajectory Diagram of Static Test.

\subsection{Results of Static and Dynamic Test}

Both static test and dynamic test belong to the category of ergonomics. Gross errors may occur in the process of test due to the inadequate accuracy of instruments, unreasonable testing procedures and negligence of the testers or staffs, which may affect the accuracy of test results. Therefore, the robust estimation theory commonly used in ergonomics was used to process the test results. After processing the exploratory M-estimator in SPSS22.0 descriptive analysis for test data, Huber's M-estimator is obtained as shown in Table 3.

Table 3. Data collation results.

\begin{tabular}{cccccccc}
\hline \multirow{2}{*}{$\begin{array}{c}\text { Amount of } \\
\text { Information }\end{array}$} & $\begin{array}{c}\text { Type of Sign } \\
\text { Layout }\end{array}$ & \multicolumn{2}{c}{$\begin{array}{c}\text { Number of Valid } \\
\text { Data }\end{array}$} & \multicolumn{2}{c}{ Visual Reaction Time } & \multicolumn{2}{c}{ Standard Error (S) } \\
& Static & Dynamic & Static & Dynamic & Static & Dynamic \\
\cline { 2 - 8 } & I & 54 & 57 & 1.522 & 1.530 & 0.083 & 0.097 \\
Three road & II & 58 & 51 & 1.735 & 1.744 & 0.064 & 0.078 \\
Information & III & 55 & 53 & 2.367 & 2.371 & 0.056 & 0.082 \\
& I & 54 & 56 & 2.735 & 2.741 & 0.075 & 0.067 \\
Six road & II & 50 & 57 & 3.059 & 3.064 & 0.091 & 0.091 \\
Information & III & 48 & 56 & 3.772 & 3.779 & 0.064 & 0.088 \\
\hline
\end{tabular}

\subsection{Validity of Static Test Results}

For each amount of information, through univariate analysis of variance, it is found that there is no significant difference in the visual reaction time measured by static and dynamic test methods. Therefore, the static test results are effective for studying drivers' dynamic recognition problem.

\subsection{Comparison of Test Results for Static Reading Time}

Under the two kinds of information quantities including three road names and six road names, draw the average value trend diagram of reading time for different graphical layouts, which is shown in Figure 4. 


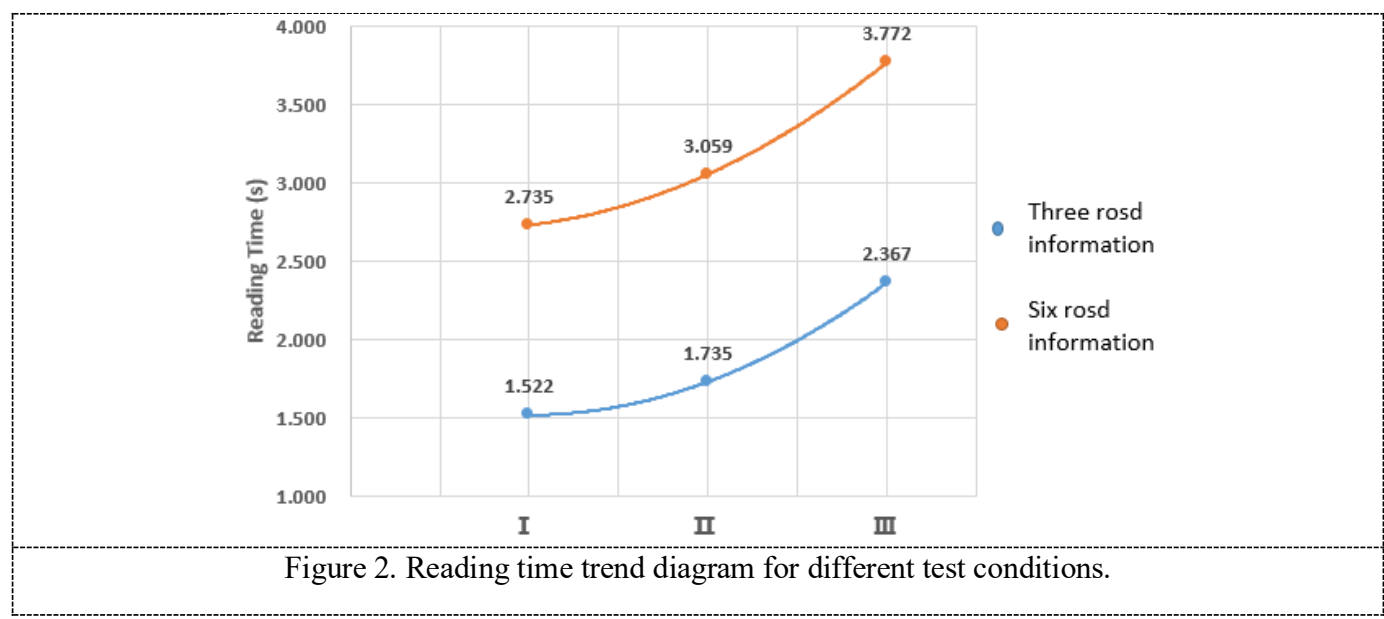

By analyzing the reading time trend diagram for different test conditions, the reading time of the test layout from I to III increases sequentially under the condition of three road name information. Comparing the graphical layouts which only show the intersecting road number information and which does not express any intersecting road information, the reading time is increased by about $0.213 \mathrm{~s}$. The graphical layout with the most intersecting road information expression has an increase of about 0.632 s for reading time compared with the graphical layout showing only the intersecting road number information. Similar to the basic trend of the three road name information condition, the reading time of the test layout from I to III also increases sequentially under the condition of six road name information. And the increaseing trend of reading time under six road information condition is more obvious.

\section{Conclusion}

According to the previous research conclusions, the drivers' cognitive time (reading time) would increase by about $400 \mathrm{~ms}$ on average for each additional information before reaching the limit information amount. The above results of the experimental data analysis show that under the condition of three road name information, comparing the graphical layout with both the intersecting road number and road name and the graphical layout which expressed none information of intersecting road for the large plane cross signs, the reading time has increased by about $0.845 \mathrm{~s}(0.213 \mathrm{~s}+0.632 \mathrm{~s})$, which is equivalent to adding 2 pieces of information. Therefore, the total amount of information on the graphical layout has reached 5, which is very close to the requirement in GB5768.2-2009 that the sum of all destination information on the guide sign layout should not exceed six. On the other hand, for the six road name information, the analysis of the reading time shows that as the number of intersecting road information increases, the reading time of the information on the sign with different graphical layouts appears more obvious increase trend. It shows that under the premise of limited cognitive resources, the increase of cognitive load will further increase the time for the driver to complete the task (in the experiment, the reading time is extended). Therefore, the six road name information cases and three road name information cases both show good consistency in the reading time test results.

\section{References}

1. BEN-BASSAT T, SHINAR D. Ergonomic. Guidelines for Traffic Sign Design Increase Sign Comprehension [J]. Human Factors: The Journal of the Human Factors and Ergonomics Society, 2006, 48(1):182-195.

2. BEN-BASSAT T, SHINAR D. The effect of context and drivers' age on highway traffic signs comprehension[J]. Transportation Research Part F Traffic Psychology \& Behavior, 2015, 33:117-127.

3. AGG HJ. Direction sign overload (project report 77) [R]. Washington D C: Transportation Research Laboratory, U.S. Department of Transportation, 1994:215-230.

4. HALL R D, MCDONALD M, RUTLEY K S. An experiment to assess the reading times of direction signs [C]/Vision in Vehicles 3d Conference. Aachen: Applied Vision Association, 1989:333350.

5. CHEN Yan-yan, JIANG Ming. Attenuation law of retroreflection coefficient for highway traffic sign retroreflective sheeting[J]. Journal of Traffic and Transportation Engineering, 2016, 16(6):107-113.

6. DI Sheng-de, JIANG Ming, JIAO Cheng-wu, et al. A study on maximum quantity of information for different kind of direction signs based on information searching time[J]. Highway, 2011(7): 255-258.

7. HOU De-zao, HUANG Kai, HAN Wen-yuan. Study on Chinese character height model for traffic guide signs based on perceive characteristics of Chinese drivers[J]. Journal of Highway and Transportation Research and Development, 2010, 27(3): 142-146.

8. YANG Man-juan, WU Lin-tao, TANG Chengcheng. Study of influence of Foreign characters in guide signs on legibility[J]. Journal of Highway and Transportation Research and Development, 2010, 27(9): 117-156. 